\title{
HTR3A and HTR3E gene polymorphisms and diarrhea predominant irritable bowel syndrome risk: evidence from a meta-analysis
}

\author{
Tangming Guan ${ }^{1, *}$, Ting $\mathrm{Li}^{1, *}{ }^{*}$, Weiming $\mathrm{Cai}^{1,2,{ }^{1},}$, Dong Huang ${ }^{1}$, Peipei Ouyang ${ }^{3}$, Yan \\ Wang ${ }^{1}$, Huayan Chen ${ }^{1}$, Kefeng $\mathrm{Wu}^{4}$ and Xiaoli Ma ${ }^{1,5}$ \\ ${ }^{1}$ Department of Pharmacy, Affiliated Hospital of Guangdong Medical University, Zhanjiang, Guangdong Province 524001, China \\ ${ }^{2}$ Laboratory of Clinical Pharmacy, Guangdong Medical University, Zhanjiang, Guangdong Province 524001, China \\ ${ }^{3}$ Department of Pharmacology, Guangdong Medical University, Zhanjiang, Guangdong Province 524001, China \\ ${ }^{4}$ Guangdong Key Laboratory for Research and Development of Natural Drug, Guangdong Medical University, Zhanjiang, \\ Guangdong Province 524001, China \\ ${ }^{5}$ Department of Clinical Pharmacy, Guangdong Medical University, Zhanjiang, Guangdong Province 524001, China \\ *These authors contributed equally to this work
}

Correspondence to: Kefeng Wu, email: winokhere@sina.com

Xiaoli Ma, email: gdmu_maxiaoli@163.com

Keywords: HTR3A, HTR3E, polymorphism, meta-analysis, diarrhea predominant irritable bowel syndrome

Received: June 12, $2017 \quad$ Accepted: July 13, $2017 \quad$ Published: July 29, 2017

Copyright: Guan et al. This is an open-access article distributed under the terms of the Creative Commons Attribution License 3.0 (CC BY 3.0), which permits unrestricted use, distribution, and reproduction in any medium, provided the original author and source are credited.

\section{ABSTRACT}

Several studies have reported an association between serotonin receptor type 3 (5-HT ${ }_{3}$ ) subunit genes HTR3A (rs1062613) and HTR3E (rs62625044) and diarrhea predominant irritable bowel syndrome (IBS-D). However, the results remain inconclusive and controversial, particularly for the data derived from different ethnicities and genders. Therefore, we performed a meta-analysis to evaluate this association. All eligible case-control studies that met the search criteria were retrieved from multiple databases, and five case-control studies were included for detailed evaluation. The pooled odds ratios (ORs) with $95 \%$ confidence intervals ( $95 \% \mathrm{CIs)}$ were calculated to assess the strengths of the associations of HTR3A (rs1062613) and HTR3E (rs62625044) polymorphisms with IBS-D risk. Our results revealed statistically significant associations of the HTR3A (rs1062613, C/T) polymorphism with a decreased risk of IBS-D in all genetic models. Additionally, the HTR3E (rs62625044, G/A) polymorphism was also found to be significantly associated with a decreased risk of IBS-D in the allele and recessive models. Subgroup analysis revealed that these associations held true especially for Asians and female. In conclusion, this meta-analysis suggested that the C allele of HTR3A (rs1062613) and the G allele of HTR3E (rs62625044) are associated with a decreased risk of IBS-D.

\section{INTRODUCTION}

Irritable bowel syndrome (IBS) is one of the most common gastrointestinal disorder characterized by abdominal discomfort, pain, and altered bowel habits; it may considerably reduce patients' quality of life and work productivity, which affects more than 7 percent of people all around the world $[1,2]$. According to the recurrent symptoms, IBS patients can experience constipation (IBS-C), diarrhea (IBS-D), or both (IBS-M) [3, 4]. IBS is a multi-factorial disorder disease associated with biological and psychosocial factors [5-9]. However, the etiology of IBS remains largely unknown. Genetic predisposition has been demonstrated in classical family/twin studies and epidemiological surveys, but unequivocal susceptibility genes have yet to be identified $[2,10]$. Recently, several genetic association studies identified the serotonin receptor type $3\left(5-\mathrm{HT}_{3}\right)$ subunit genes HTR $3 A$ and HTR $3 E$ polymorphisms as being significantly associated with IBS ( particularly IBS-D) [11-14]. 
The 5- $\mathrm{HT}_{3}$ receptor is a Cys-loop ligand-gated ion channel composed of five subunits [15], which are encoded by the HTR $3 A, H T R 3 B, H T R 3 C, H T R 3 D$ and HTR $3 E$ genes [16-18]. Different HTR3 variants have been reported to be associated with schizophrenia [19], depression [20], anxiety [21], autism [22], obsessive compulsive disorder (OCD) [23], drug abuse and addiction [24, 25]. Recently, the associations between these two HTR3 polymorphisms (HTR $3 A$ and HTR3E) and the risk of IBS-D have been intensively investigated. However, the community is still unable to reach a consensus, particularly regarding the data from different ethnicities and genders [11-14, 26]. Such inconsistencies are generally due to ethnic differences or variations in sample size. Hence, we designed this metaanalysis to quantify the overall genetic effects of the HTR $3 A$ and HTR $3 E$ polymorphisms on the risk of IBS-D.

\section{RESULTS}

\section{Characteristics of studies}

As showed in Figure 1, 5 studies involving 1,287 cases and 1,418 controls were ultimately included in the present meta-analysis. Regarding the HTR3A (rs1062613, $\mathrm{C} / \mathrm{T}$ ) polymorphism, 5 studies were available and included a total of 1,178 cases and 1,124 controls. Regarding the HTR3E (rs62625044, G/A) polymorphism, 5 studies involving a total of 1,276 cases and 1,389 controls were available. All of these included studies were hospital-based, of which 3 from China, 1 from Germany, 1 from USA. Additionally, all of the included studies were of high quality, as indicated by the Newcastle-Ottawa scale (NOS) scores of each study being above 6 points (see Supplementary Table 1), and the genotype distributions in all of the controls were consistent with Hardy-Weinberg equilibrium (HWE), except one [6]. Studies with controls not in HWE were also considered for the meta-analysis, but they were excluded in the sensitivity analysis. The main characteristics of the included studies were summarized in Table 1.

\section{Power analysis}

Before implementation of this meta-analysis, statistical power was assessed with the assumptions: $\alpha$ err prob $=0.05, \mathrm{OR}=1.30$ (corresponding to a "weak to moderate" gene effect) for the two single nucleotide polymorphisms (SNPs), and minor allele frequencies (MAF) of HTR3A (rs1062613, C/T) and HTR3E (rs62625044, G/A) were estimated from the 1000 Genomes. The present samples indicated that $97.8 \%$ power for HTR3A (rs1062613, C/T) $(\mathrm{MAF}=0.25)$, and 17.5\%

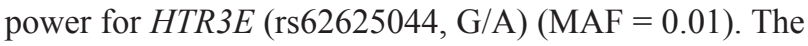
power analysis indicated that these recruited samples could provide sufficient power in identifying the association between HTR3A (rs1062613, C/T) polymorphism and IBS-D.

\section{Quantitative synthesis}

As illustrated in Figures 2-3, different genetic models of HTR3A (rs1062613, C/T) and HTR3E (rs62625044, G/A) were used in our analysis.

The C allele of rs1062613 was found to be significantly associated with a decreased risk of IBS-D.

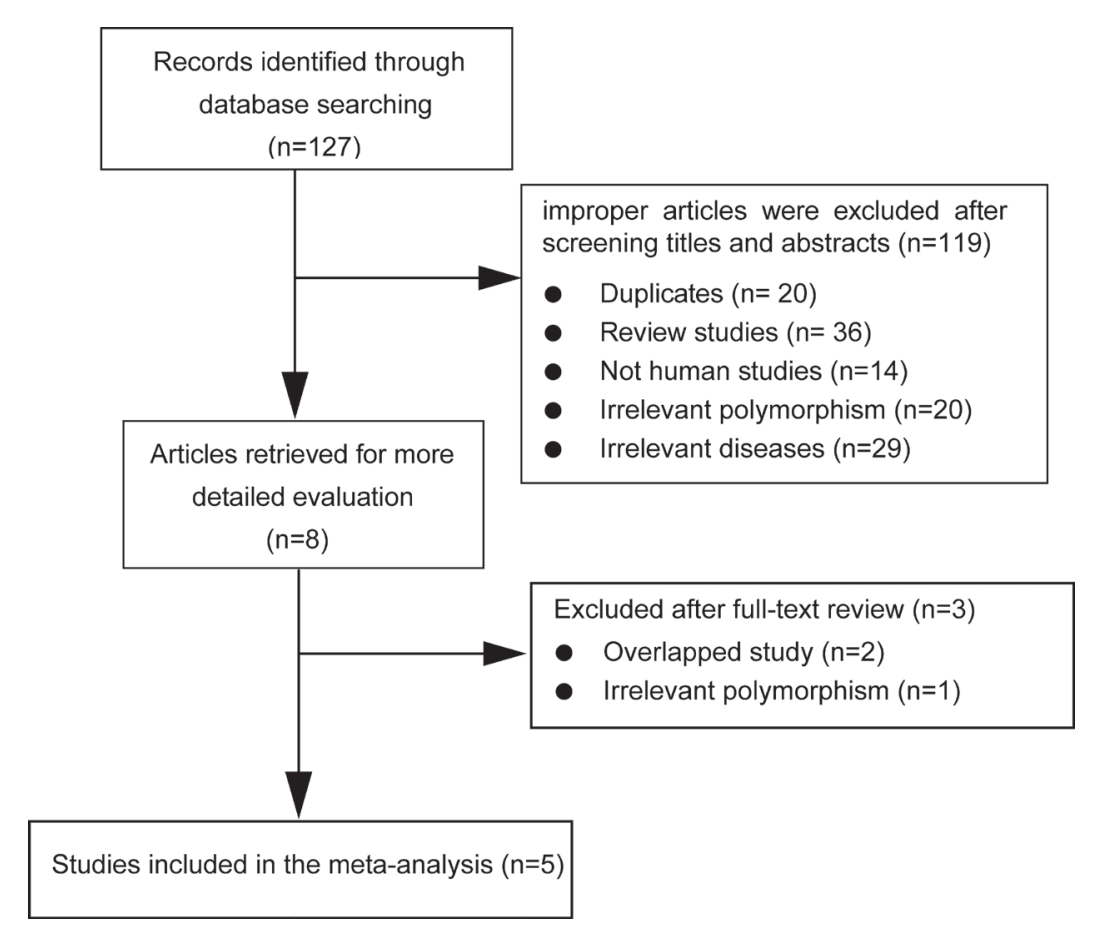

Figure 1: Flow diagram of selection of eligible studies. 
Table 1: Characteristics of studies included in the meta-analysis

\begin{tabular}{|c|c|c|c|c|c|c|c|c|c|c|c|c|c|c|}
\hline \multirow{2}{*}{ Study } & \multirow{2}{*}{ Country } & \multirow{2}{*}{ Ethnicity } & \multirow{2}{*}{ Design } & \multicolumn{3}{|c|}{$\begin{array}{c}\text { HTR3A } \\
\text { (case/control) }\end{array}$} & \multicolumn{3}{|c|}{$\begin{array}{c}\text { HTR3E } \\
\text { (case/control) }\end{array}$} & \multirow{2}{*}{$\begin{array}{l}\text { Genotyping } \\
\text { Method }\end{array}$} & \multirow{2}{*}{$\begin{array}{c}\text { Diagnosis } \\
\text { criteria }\end{array}$} & \multicolumn{2}{|c|}{ HWE (P) } & \multirow[t]{2}{*}{ NOS } \\
\hline & & & & $\mathrm{CC}$ & CT & TT & GG & GA & $\mathbf{A A}$ & & & HTR3A & HTR3E & \\
\hline Gu 2015 & China & Asian & HB & $\begin{array}{l}299 / \\
340\end{array}$ & $\begin{array}{l}155 / \\
114\end{array}$ & $\begin{array}{l}46 / \\
16\end{array}$ & $\begin{array}{l}429 / \\
453\end{array}$ & $\begin{array}{l}71 / \\
47\end{array}$ & $\begin{array}{l}0 / \\
0\end{array}$ & $\begin{array}{l}\text { PCR and } \\
\text { RFLP }\end{array}$ & Rome II & 0.87 & 0.27 & 6 \\
\hline $\begin{array}{l}\text { Kapeller } 1 \\
2008\end{array}$ & Germany & $\begin{array}{l}\text { Caucasian } \\
\text { (UK) }\end{array}$ & HB & $\begin{array}{l}55 / \\
72\end{array}$ & $\begin{array}{l}35 / \\
26\end{array}$ & $\begin{array}{l}8 / \\
2\end{array}$ & $\begin{array}{l}88 / \\
94\end{array}$ & $\begin{array}{c}12 / \\
6\end{array}$ & $\begin{array}{l}0 / \\
0\end{array}$ & $\begin{array}{l}\text { PCR and } \\
\text { sequencing }\end{array}$ & Rome II & 0.84 & 0.76 & 7 \\
\hline $\begin{array}{c}\text { Kapeller } 2 \\
2008\end{array}$ & Germany & $\begin{array}{l}\text { Caucasian, } \\
\text { (Germany) }\end{array}$ & HB & $\begin{array}{l}76 / \\
121\end{array}$ & $\begin{array}{l}36 / \\
63\end{array}$ & $\begin{array}{l}7 / \\
11\end{array}$ & $\begin{array}{l}107 / \\
189\end{array}$ & $\begin{array}{c}12 / \\
5\end{array}$ & $\begin{array}{l}0 / \\
1\end{array}$ & $\begin{array}{l}\text { PCR and } \\
\text { sequencing }\end{array}$ & Rome II & 0.46 & 0.00 & 7 \\
\hline $\begin{array}{c}\text { Kilpatrick } \\
2011\end{array}$ & USA & American & HB & $\begin{array}{l}8 / \\
15\end{array}$ & $\begin{array}{l}3 / \\
12\end{array}$ & $\begin{array}{l}0 / \\
2\end{array}$ & - & - & - & TaqMan & Rome II & 0.85 & - & 7 \\
\hline $\begin{array}{l}\text { Zhang } \\
2013\end{array}$ & China & Asian & HB & $\begin{array}{l}269 / \\
204\end{array}$ & $\begin{array}{c}140 / \\
87\end{array}$ & $\begin{array}{c}41 / \\
9\end{array}$ & $\begin{array}{l}386 / \\
272\end{array}$ & $\begin{array}{l}64 / \\
28\end{array}$ & $\begin{array}{l}0 / \\
0\end{array}$ & $\begin{array}{l}\text { PCR and } \\
\text { RFLP }\end{array}$ & Rome III & 0.64 & 0.59 & 6 \\
\hline $\begin{array}{c}\text { Zhang } \\
2016\end{array}$ & China & Asian & HB & - & - & - & $\begin{array}{l}90 / \\
274\end{array}$ & $\begin{array}{l}17 / \\
20\end{array}$ & $\begin{array}{l}0 / \\
0\end{array}$ & $\begin{array}{l}\text { PCR and } \\
\text { RFLP }\end{array}$ & Rome III & - & 0.55 & 7 \\
\hline
\end{tabular}

Abbreviations: HB, hospital-based study; PB, population based; Uk, United Kingdom.

RFLP, restriction fragment length polymorphism analyses.

The following data were obtained: in the allele model, C vs. T, $\mathrm{OR}=0.73,95 \% \mathrm{CI}: 0.56-0.95$, and $P=0.02$; in the codominant model, CC vs. TT, OR $=0.36,95 \%$ CI: $0.25-0.53, P<0.00001 ;$ CT vs. TT, OR $=0.42,95 \%$ CI: $0.28-0.64$, and $P<0.0001$; in the dominant model, $\mathrm{CC}+\mathrm{CT}$ vs. TT, $\mathrm{OR}=0.38,95 \% \mathrm{CI}: 0.26-0.56$ and $P<$ 0.0001 ; and recessive (CC vs. $\mathrm{CT}+\mathrm{TT}, \mathrm{OR}=0.73,95 \%$ CI: $0.62-0.87, P=0.0004$ ) (Figure 2). In the subgroup analyses by ethnicity, the significant association was found among Asians (C vs. T, OR $=0.65,95 \%$ CI: $0.55-0.77, P<0.00001 ; \mathrm{CC}$ vs. TT, OR $=0.30,95 \%$ CI: $0.19-0.47, P<0.00001 ;$ CT vs. TT, OR $=0.37,95 \%$ CI: $0.23-0.59, P<0.0001 ; \mathrm{CC}+\mathrm{CT}$ vs. TT, $\mathrm{OR}=0.32$, 95\% CI: $0.20-0.50, P<0.00001 ; \mathrm{CC}$ vs. CT $+\mathrm{TT}$, $\mathrm{OR}=0.70,95 \% \mathrm{CI}: 0.57-0.85, P=0.0004$ ), while no significant association was found among non-Asians. In addition, analysis stratified by different gender showed a significant association of IBS risk with the $\mathrm{C}$ allele deletion in both female and male. All the results are listed in Table 2.

The $G$ allele of rs62625044 was found to be significantly associated with a decreased risk of ISB-D in allele model (G vs. A, OR $=0.57,95 \%$ CI: $0.44-0.73, P$ $<0.00001)$ and recessive model (GG vs. GA+AA, OR $=$ $0.55,95 \%$ CI: $0.42-0.71, P<0.00001$ ) (Figure 3). In the subgroup analyses by ethnicity, the significant association was found both in Asians (G vs. A, OR $=0.60,95 \%$ CI: $0.46-0.79, P=0.0002$; GG vs. GA+AA, $\mathrm{OR}=0.58$, 95\% CI: $0.44-0.77, P=0.0001$ ) and non-Asians (G vs. A, OR $=0.38,95 \%$ CI: $0.19-0.77, P=0.007$; GG vs. $\mathrm{GA}+\mathrm{AA}, \mathrm{OR}=0.36,95 \% \mathrm{CI}: 0.18-0.75, P=0.006)$. In addition, analysis stratified by different gender showed a significant association of IBS-D risk with the $G$ allele deletion in female $(\mathrm{G}$ vs. A, OR $=0.41,95 \%$ CI: 0.30 $0.56, P<0.00001 ; \mathrm{GG}$ vs. $\mathrm{GA}+\mathrm{AA}, \mathrm{OR}=0.39,95 \% \mathrm{CI}$ : $0.28-0.54, P<0.00001)$, but not in male. All the results are listed in Table 2.

\section{Sensitivity analysis}

Sensitivity analysis of the summary odds ratio coefficients on the relationships of the two SNPs and the risk of IBS-D is computed by omitting each study in turn. The corresponding pooled ORs were not significantly altered after excluding each eligible study at a time (Figures 4-5).

\section{Publication bias}

No evidence of publication bias was detected regarding the ORs of the two SNPs in this study by either Begg's or Egger's test (Table 3).

\section{DISCUSSION}

Recently, several genetic association studies identified a novel association between HTR3 (HTR3A and $H T R 3 E$ ) and IBS-D. In Europe, Kapeller J [11] found that the novel HTR3E variant c.*76G $>$ A (rs62625044) is significantly associated with female IBS-D in two independent cohorts from the UK and Germany, while the HTR3A variant c. $-42 \mathrm{C}>\mathrm{T}$ (rs 1062613) is only associated with the risk for IBS-D in UK, but not in Germany population. In Asia, Gu et al. [13] demonstrated that genetic polymorphisms in HTR $3 A$ and HTR $3 E$ are associated with the risk for D-IBS in Chinese population, especially in women. However, another studies [26] revealed that the HTR $3 A$ polymorphism loci rs1062613 may be not associated with IBS risk in American population. Due to relatively small samples from different populations, these studies demonstrated inconsistent results. Therefore, we performed a metaanalysis to estimate the association between HTR $3 A$ and HTR $3 E$ polymorphisms and the risk for IBS-D. To the best of our knowledge, this is the first meta-analysis to 
explore the relationships between HTR3A and HTR3E gene polymorphisms and IBS-D susceptibility. Five casecontrol studies [11-14, 26] with a total of 1,287 IBS-D patients and 1,418 healthy controls were included in our meta-analysis, which was giving a greater power to detect IBS-D risk associated with HTR $3 A$ and HTR $3 E$ gene polymorphisms.

In our meta-analysis, the main finding was that the $\mathrm{C}$ allele of HTR3A (rs1062613) decreases the risk of IBS-D in all of the comparison models, and the $\mathrm{G}$ allele of HTR $3 E$ (rs62625044) was also observed to have lower IBS-D risk in the allele and recessive models. Besides that, subgroup analyses by ethnicity indicated that SNP of rs62625044 (G/A) was significantly associated with a decreased risk of IBS-D in both Asian and non-Asian population, while the SNP of rs1062613(C/T) was only associated with the risk for IBS-D in Asian population. Moreover, analyses stratified by different gender showed a significant association between $\mathrm{rs} 1062613(\mathrm{C} / \mathrm{T})$ polymorphism and risk of IBS-D in both female and male population, while the SNP of rs62625044 (G/A) was only associated with risk of IBS-D in female population. Our results have some differences from the previous studies $[11,26]$. A possible explanation for this phenomenon is that the

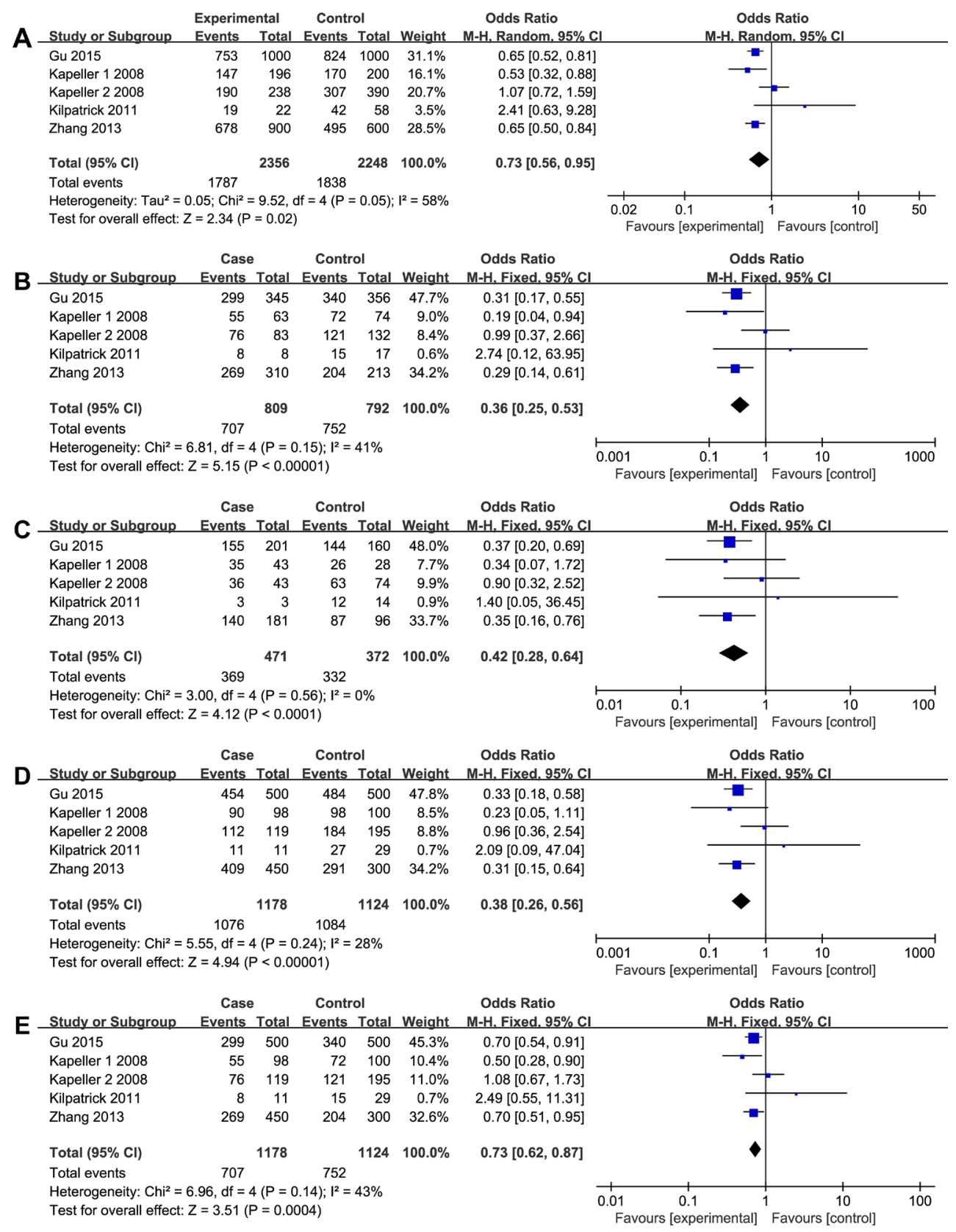

Figure 2: The associations of $\operatorname{HTR} 3 \boldsymbol{A}(\mathbf{r s 1 0 6 2 6 1 3}, \mathrm{C} / \mathrm{T})$ with ISB-D in different genetic models. (A) Allele model (C vs. T). (B) Codominant model (CC vs. TT). (C) Codominant model (CT vs. TT). (D) Dominant model (CC + CT vs. TT). (E) Recessive model (CC vs. TT + CT). 
Table 2: Summary of meta-analysis for the association of HTR3E (rs62625044, G/A) and HTR3E (rs62625044, G/A) polymorphisms with ISB-D

\begin{tabular}{|c|c|c|c|c|c|c|}
\hline \multirow{2}{*}{ Genetic model } & \multirow{2}{*}{ Stratifications } & \multirow{2}{*}{$\begin{array}{l}\text { Number of } \\
\text { studies }\end{array}$} & \multirow{2}{*}{ OR $(95 \% C I)$} & \multirow{2}{*}{$P$ value } & \multicolumn{2}{|c|}{ Heterogeneity } \\
\hline & & & & & $I^{2}$ & $P_{\mathrm{H}}$ \\
\hline \multicolumn{7}{|c|}{ HTR3A (rs1062613, C/T) } \\
\hline \multirow[t]{5}{*}{ C vs. T } & Overall & 5 & $0.73[0.56,0.95]$ & 0.02 & $58 \%$ & 0.05 \\
\hline & Asians & 2 & $0.65[0.55,0.77]$ & $<0.00001$ & $0 \%$ & 0.98 \\
\hline & Non-Asians & 3 & $0.93[0.47,1.82]$ & 0.82 & $71 \%$ & 0.03 \\
\hline & female & 5 & $0.71[0.60,0.85]]$ & 0.0001 & $32 \%$ & 0.21 \\
\hline & male & 4 & $0.61[0.46,0.81]$ & 0.0006 & $30 \%$ & 0.24 \\
\hline \multirow[t]{5}{*}{ CC vs. TT } & Overall & 5 & $0.36[0.25,0.53]$ & $<0.00001$ & $41 \%$ & 0.15 \\
\hline & Asians & 2 & $0.30[0.19,0.47]$ & $<0.00001$ & $0 \%$ & 0.91 \\
\hline & Non-Asians & 3 & $0.65[0.31,1.37]$ & 0.26 & $47 \%$ & 0.26 \\
\hline & female & 5 & $0.40[0.26,0.61]$ & $<0.0001$ & $0 \%$ & 0.41 \\
\hline & male & 4 & $0.20[0.07,0.57]$ & 0.002 & $27 \%$ & 0.25 \\
\hline \multirow[t]{5}{*}{ CT vs. TT } & Overall & 5 & $0.42[0.28,0.64]$ & $<0.0001$ & $0 \%$ & 0.56 \\
\hline & Asians & 2 & $0.37[0.23,0.59]$ & $<0.0001$ & $0 \%$ & 0.91 \\
\hline & Non-Asians & 3 & $0.69[0.31,1.54]$ & 0.36 & $0 \%$ & 0.56 \\
\hline & female & 5 & $0.46[0.30,0.72]$ & 0.0006 & $0 \%$ & 0.77 \\
\hline & male & 4 & $0.25[0.08,0.73]$ & 0.01 & $0 \%$ & 0.43 \\
\hline \multirow[t]{5}{*}{$\mathrm{CC}+\mathrm{CT}$ vs. TT } & Overall & 5 & $0.38[0.26,0.56]$ & $<0.00001$ & $28 \%$ & 0.24 \\
\hline & Asians & 2 & $0.32[0.20,0.50]$ & $<0.00001$ & $0 \%$ & 0.91 \\
\hline & Non-Asians & 3 & $0.66[0.31,1.39]$ & 0.27 & $29 \%$ & 0.25 \\
\hline & female & 5 & $0.42[0.28,0.63]$ & $<0.0001$ & $0 \%$ & 0.52 \\
\hline & male & 4 & $0.22[0.08,0.60]$ & 0.003 & $21 \%$ & 0.29 \\
\hline \multirow[t]{5}{*}{ CC vs. $\mathrm{CT}+\mathrm{TT}$} & Overall & 5 & $0.73[0.62,0.87]$ & 0.0004 & $43 \%$ & 0.14 \\
\hline & Asians & 2 & $0.70[0.57,0.85]$ & 0.0004 & $0 \%$ & 1.00 \\
\hline & Non-Asians & 3 & $0.91[0.44,1.89]$ & 0.80 & $67 \%$ & 0.05 \\
\hline & female & 5 & $0.75[0.61,0.93]$ & 0.008 & $0 \%$ & 0.40 \\
\hline & male & 4 & $0.66[0.48,0.90]$ & 0.009 & $5 \%$ & 0.37 \\
\hline \multicolumn{7}{|c|}{ HTR3E (rs62625044, G/A) } \\
\hline \multirow[t]{5}{*}{ G vs. A } & Overall & 5 & $0.57[0.44,0.73]$ & $<0.00001$ & $0 \%$ & 0.49 \\
\hline & Asians & 3 & $0.60[0.46,0.79]$ & 0.0002 & $0 \%$ & 0.47 \\
\hline & Non-Asians & 2 & $0.38[0.19,0.77]$ & 0.007 & $0 \%$ & 0.49 \\
\hline & female & 5 & $0.41[0.30,0.56]$ & $<0.00001$ & $0 \%$ & 0.59 \\
\hline & male & 4 & $1.09[0.71,1.68]$ & 0.69 & $0 \%$ & 0.97 \\
\hline \multirow[t]{5}{*}{ GG vs. GA+AA } & Overall & 5 & $0.55[0.42,0.71]$ & $<0.00001$ & $0 \%$ & 0.49 \\
\hline & Asians & 3 & $0.58[0.44,0.77]$ & 0.0001 & $0 \%$ & 0.46 \\
\hline & Non-Asians & 2 & $0.36[0.18,0.75]$ & 0.006 & $0 \%$ & 0.49 \\
\hline & female & 5 & $0.39[0.28,0.54]$ & $<0.00001$ & $0 \%$ & 0.59 \\
\hline & male & 4 & $1.10[0.70,1.72]$ & 0.68 & $0 \%$ & 0.97 \\
\hline
\end{tabular}

previous single studies of IBS-D had small samples size, and thus the significance of current work may not be justified; thus, further studies are needed to clarify the effects of the 2 SNPs on the risk of IBS-D. Furthermore, the differential allele frequencies of the 2 SNPs exerted disproportionate levels of influence on the IBS-D risks in different populations. For example, the minor allele frequencies (MAFs) of the 2 SNPs rs 1062613 and rs62625044 are 0.147 and 0.000 , respectively, in the East Asian population (EAS), whereas the MAFs are 0.169 and 
Table 3: Publication bias tests for association of the HTR3A (rs1062613, C/T) and HTR3E (rs62625044, G/A) polymorphisms with ISB-D

\begin{tabular}{lcccc}
\hline \multirow{2}{*}{ Comparisons } & \multicolumn{3}{c}{ Egger test } & Begg test \\
\cline { 2 - 5 } HTR3A (rs1062613, C/T) & Coefficient & $\boldsymbol{P}$ value & $\mathbf{9 5 \%}$ CI & $\boldsymbol{P}$ value \\
C vs. T & 1.81 & 0.30 & $(-2.78,6.41)$ & 0.81 \\
CC vs. TT & 1.20 & 0.44 & $(-3.12,5.53)$ & 0.81 \\
CT vs. TT & 0.88 & 0.39 & $(-1.91,3.68)$ & 0.22 \\
CC+CT vs. TT & 1.09 & 0.44 & $(-2.81,4.99)$ & 0.22 \\
CC vs. CT+TT & 1.32 & 0.40 & $(-2.98,5.61)$ & 0.81 \\
HTR3E (rs62625044, G/A) & & & & \\
G vs. A & -1.53 & 0.23 & $(-5.38,2.31)$ & 0.31 \\
GG vs. GA+AA & -1.56 & 0.23 & $(-5.51,2.39)$ & 0.31 \\
\hline
\end{tabular}

0.019, respectively, in the Ad Mixed American population (AMR) and the MAFs are 0.218 and 0.028 , respectively, in the European population (EUR) based on the data from the 1000 G. Finally, significant heterogeneity was observed in allele model of rs62625044, and factors, such as ethnicity, gender distribution, psychosocial, genotyping method and other, might be potential sources of heterogeneity.

Additionally, the genotype distributions in all of the controls were consistent with HWE, except one for one study reported by Kapeller et al. [11]. However, the association was not significant change when excluded the study. The NOS results indicated that the included studies were credible. Moreover, sensitivity analysis was conducted, and it did not significantly alter the combined ORs. Additionally, no evidence of publication bias was identified by either Begg's or Egger's tests. Taken together, the results of this meta-analysis are reliable and stable.
There were some limitations in the current study. Firstly, the sample sizes of the studies included in our meta-analysis were relatively small, especially in the subgroup of non-Asians, which may lead to a false negative result. Therefore, the negative results of the nonAsians should be interpreted with caution. Moreover, although meta-analysis has the benefit to overcome this limitation and may generate more precise results, the combined sample sizes in our meta-analysis were still inadequate to detect the association between rs62625044 polymorphism and IBS-D risk because power calculation for the pooled sample sizes was less than $80 \%$, which might attenuate the statistical power to detect a slight effect and increase the chance of opportunity bias. Second, due to the limited data, we did not carry out subgroup analysis to other factors, which may participate in the progression of IBS-D, such as age, lifestyle and social

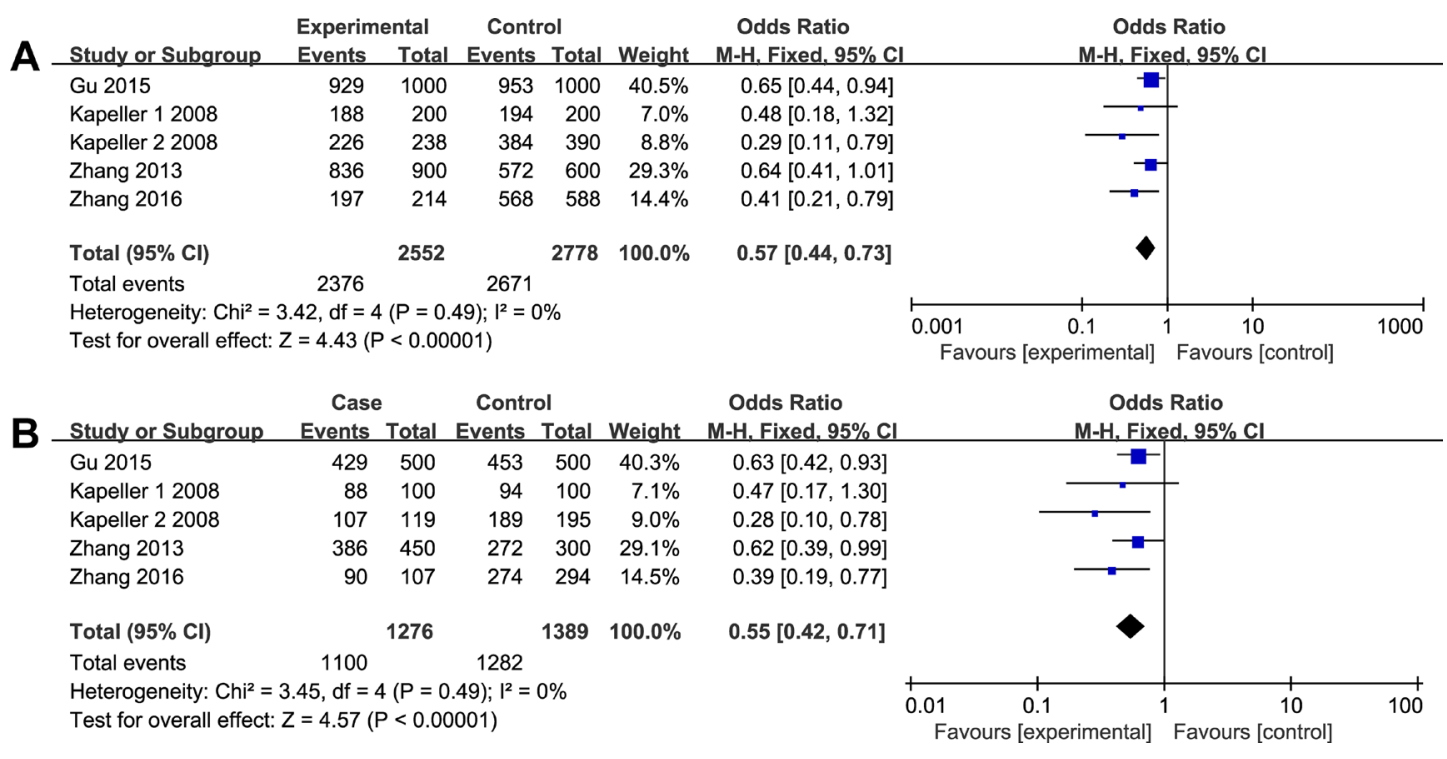

Figure 3: The associations of $\boldsymbol{H T R} 3 \boldsymbol{E}$ (rs62625044, G/A) with ISB-D in different genetic models. (A) Allele model (G vs. A). (B) Recessive model (GG vs. GA+AA). 

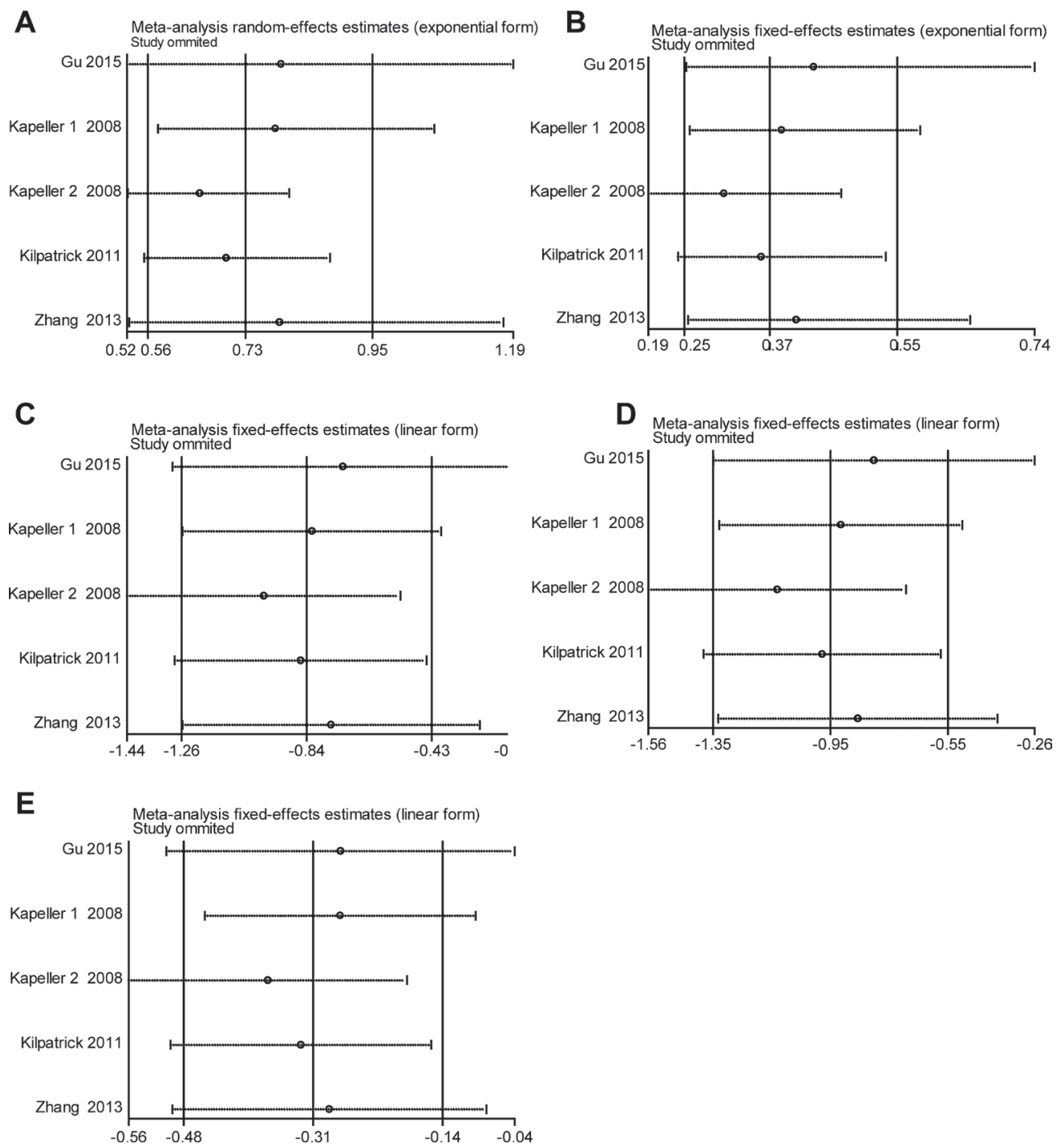

Figure 4: Sensitivity analysis of the association of HTR3A (rs1062613, C/T) and ISB-D in the different genetic models. (A) Allele model (C vs. T). (B) Codominant model (CC vs. TT). (C) Codominant model (CT vs. TT). (D) Dominant model (CC + CT vs. TT). (E) Recessive model (CC vs. TT + CT).
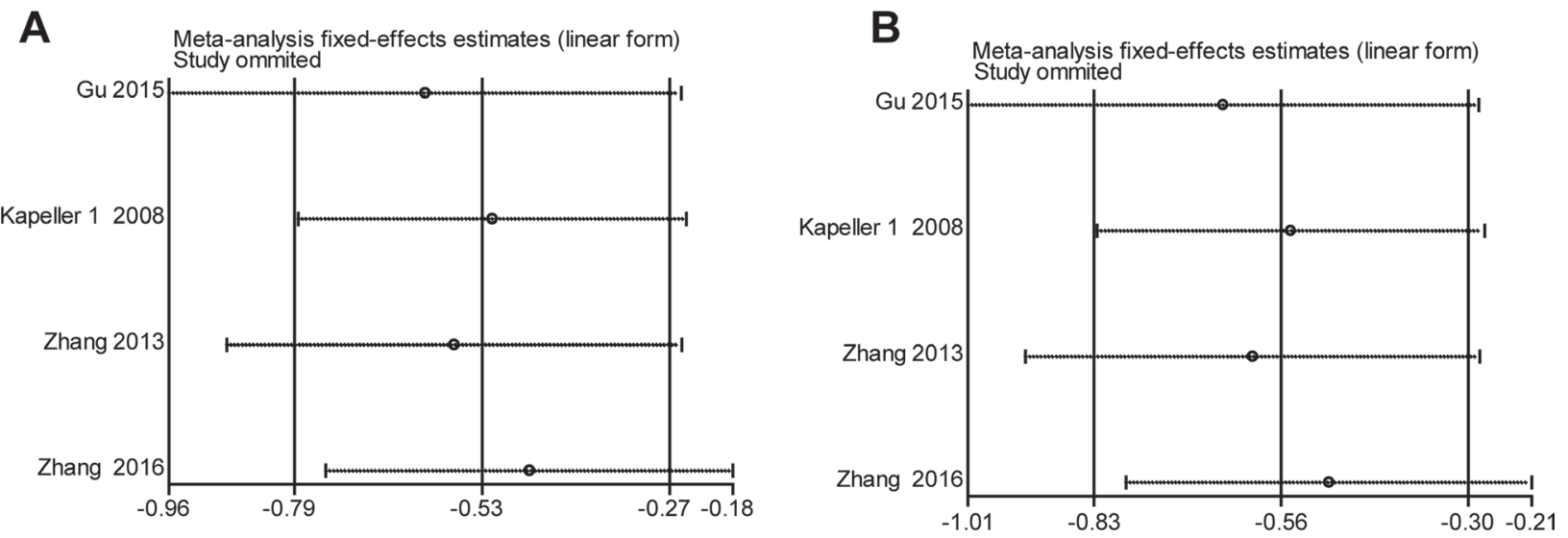

Figure 5: Sensitivity analysis of the association of HTR3E (rs62625044, G/A) and ISB-D in the different genetic models. (A) Allele model (G vs. A). (B) Recessive model (GG vs. AA + AG). 
psychology. Thirdly, only articles in English and Chinese language were included; thus, studies written in other languages were neglected. Finally, although we performed a systematic searching strategy to identify eligible studies, there was still probability that few studies so called "grey literatures" were not included.

In conclusion, this meta-analysis suggested that the C allele of HTR3A (rs1062613) and the G allele of HTR3E (rs62625044) are associated with a decreased risk of IBS-D. One evidence indicates that these HTR3 polymorphisms can remarkably up-regulate the expression of $5-\mathrm{HT}_{3}$ receptors, which have been proved to cause the gastric functional disorders including emesis, eating disorders and IBS-D, et al. [27], as illustrated in Supplementary Figure 1. Due to the above-mentioned limitations, a well-designed large-scale study that includes ethnicities, genders and psychosocial factors is required to confirm the findings of the current meta-analysis.

\section{MATERIALS AND METHODS}

\section{Search strategy}

In accordance with the Preferred Reporting Items for Systematic Reviews and Meta-Analyses (PRISMA) statement [28], we searched the related literature of the electronic records of the PubMed, Science Direct, Embase, WANFANG databases and Chinese National Knowledge Infrastructure (CNKI) published through 30 March 2017. The search terms included the following key words: ("Irritable bowel syndrome" or "IBS") AND ("polymorphism" or "allele" or "genetic" or "gene" or "mutation" or "variant") AND ("serotonin type 3" or "serotonin receptor 3 " or " $5-\mathrm{HT}_{3}$ " or "HTR $3 A$ " or “HTR3E”). Furthermore, the references of all retrieved articles were also checked by hand to identify additional potential studies. The languages were limited to English and Chinese.

\section{Inclusion criteria}

The inclusion criteria were as follows: (1) studies of the association between HTR $3 A$ or HTR $3 E$ polymorphism and IBS; (2) cohort or case-control study (3) provided sufficient data of allele and genotype frequencies of SNPs or required information could be calculated; and (4) if serial studies on the same population were published, only the most recent study was included. Additionally, we excluded reviews, abstracts, and redundant and animal studies.

\section{Data extraction}

Two independent investigators extracted relevant data from all included studies on the basis of the inclusion criteria, and a third investigator verified them. The following information from eligible studies was extracted: the first author's name, publication year, country of origin, ethnicity, sample size, genotyping method, and the $H T R 3 A$ and HTR $3 E$ genotype distributions and alleles in the case and control groups.

\section{Quality assessment}

The quality of included studies were assessed by two investigators independently on the basis of NewcastleOttawa Scale (NOS) [29], which based on three aspects: selection, comparability and exposure. Studies with a score of 5 points or higher were considered to be of high quality.

\section{Statistical analysis}

The HWE of the genotype distributions in the controls of the include studies were tested by the Chisquare test, $P<0.05$ was considered statistically significant. Studies with the controls not in HWE were subjected to a sensitivity analysis [30]. The power analysis was calculated by using the Power and Sample Size Program software [31]. The associations of the HTR $3 A$ and HTR $3 E$ polymorphisms with the risk of IBS were assessed by the pooled ORs with the corresponding 95\% CIs under the following genetic models: allele model, codominant model, dominant model, and recessive model. The heterogeneity between studies was determined by the Cochrane's Q-statistic test [32], and the inconsistency was quantified with the $I^{2}$ statistic. When $I^{2}>50 \%$ or $P_{Q} \leq 0.1$, which suggest substantial heterogeneity, a random-effects model (DerSimonian-Laird method) [33] was used; otherwise, the fixed-effects model (Mantel-Haenszel method) [28] was applied. Sensitivity analysis was conducted by sequentially omitting each study to validate the reliability of the results. Publication bias was examined with Begg's funnel plot and Egger's test [34], and $P<0.05$ was considered statistically significant. All analyses were conducted using the RevMan 5.1 and STATA 12.0 software packages.

\section{Abbreviations}

5-HT3:serotonin receptor type 3; IBS:Irritable bowel syndrome; IBS-D:diarrhea predominant irritable bowel syndrome; ORs:odds ratios; 95\% CIs:95\% confidence intervals; HWE:Hardy-Weinberg equilibrium; SNPs:single nucleotide polymorphisms, MAF: minor allele frequencies; EAS:East Asian population; AMR:Ad Mixed American population; EUR:European population; CNKI:Chinese National Knowledge Infrastructure; PRISMA:Preferred Reporting Items for Systematic Reviews and Meta-Analyses; NOS:Newcastle-Ottawa Scale. 


\section{Author contributions}

Study Conception and Design: TMG, XLM and KFW. Acquisition of data: TL, DH and WMC. Preparation of figures:YW, PPOY and DH. Preparation of tables: TL, DH, HYC and YW. Writing and revision of the manuscript: TMG, KFW and XLM.

\section{ACKNOWLEDGMENTS}

We thank the hospital for providing a good research platform for us, and thank the family for their support and understand in work and study.

\section{CONFLICTS OF INTEREST}

The authors declare no conflicts of interest.

\section{REFERENCES}

1. Chey WD, Kurlander J, Eswaran S. Irritable bowel syndrome: a clinical review. JAMA. 2015; 313:949-58. https://doi.org/10.1001/jama.2015.0954.

2. Sperber AD, Dumitrascu D, Fukudo S, Gerson C, Ghoshal UC, Gwee KA, Hungin APS, Kang JY, Minhu C, Schmulson M, Bolotin A, Friger M, Freud T, et al. The global prevalence of IBS in adults remains elusive due to the heterogeneity of studies: a Rome Foundation working team literature review. Gut. 2017; 66:1075-82. https://doi. org/10.1136/gutjnl-2015-311240.

3. Drossman DA. The functional gastrointestinal disorders and the Rome III process. Gastroenterology. 2006; 130:137790. https://doi.org/10.1053/j.gastro.2006.03.008.

4. Longstreth GF, Thompson WG, Chey WD, Houghton LA, Mearin F, Spiller RC. Functional bowel disorders. Gastroenterology. 2006; 130:1480-91. https://doi. org/10.1053/j.gastro.2005.11.061.

5. Holtmann G, Goebell H, Jockenhoevel F, Talley NJ. Altered vagal and intestinal mechanosensory function in chronic unexplained dyspepsia. Gut. 1998; 42:501-6.

6. Camilleri M. Peripheral mechanisms in irritable bowel syndrome. N Engl J Med. 2012; 367:1626-35. https://doi. org/10.1056/NEJMra1207068.

7. Nourrisson C, Scanzi J, Pereira B, NkoudMongo C, Wawrzyniak I, Cian A, Viscogliosi E, Livrelli V, Delbac F, Dapoigny M, Poirier P. Blastocystis is associated with decrease of fecal microbiota protective bacteria: comparative analysis between patients with irritable bowel syndrome and control subjects. PLoS One. 2014; 9:e111868. https://doi.org/10.1371/journal.pone.0111868.

8. Arisawa T, Tahara T, Shiroeda H, Minato T, Matsue Y, Saito T, Fukuyama T, Otsuka T, Fukumura A, Nakamura M, Shibata T. Genetic polymorphisms of SCN10A are associated with functional dyspepsia in Japanese subjects.
J Gastroenterol. 2013; 48:73-80. https://doi.org/10.1007/ s00535-012-0602-3.

9. Zheng Z, Tang H. Decreased neuroplasticity may play a role in irritable bowel syndrome: implication from the comorbidity of depression and irritable bowel syndrome. J Neurogastroenterol Motil. 2015; 21:298-9. https://doi. org/10.5056/jnm14158.

10. Gazouli M, Wouters MM, Kapur-Pojskic L, Bengtson MB, Friedman E, Nikcevic G, Demetriou CA, Mulak A, Santos J, Niesler B. Lessons learned--resolving the enigma of genetic factors in IBS. Nat Rev Gastroenterol Hepatol. 2016; 13:77-87. https://doi.org/10.1038/nrgastro.2015.206.

11. Kapeller J, Houghton LA, Monnikes H, Walstab J, Moller D, Bonisch H, Burwinkel B, Autschbach F, Funke B, Lasitschka F, Gassler N, Fischer C, Whorwell PJ, et al. First evidence for an association of a functional variant in the microRNA-510 target site of the serotonin receptortype $3 \mathrm{E}$ gene with diarrhea predominant irritable bowel syndrome. Hum Mol Genet. 2008; 17:2967-77. https://doi. org/10.1093/hmg/ddn195.

12. Zhang Y, Huang Y, Bo P. Association between diarrheapredominant irritable bowel syndrome and HTR3A, HTR3E gene polymorphism in Yangzhou,Jiangsu province, China. [Article in Chinese]. Zhonghua Liu Xing Bing Xue Za Zhi. $2013 ; 34: 721-4$.

13. Gu QY, Zhang J, Feng YC, Dai GR, Du WP. Association of genetic polymorphisms in HTR3A and HTR3E with diarrhea predominant irritable bowel syndrome. Int J Clin Exp Med. 2015; 8:4581-5.

14. Zhang Y, Li Y, Hao Z, Li X, Bo P, Gong W. Association of the Serotonin Receptor 3E Gene as a Functional Variant in the MicroRNA-510 Target Site with Diarrhea Predominant Irritable Bowel Syndrome in Chinese Women. J Neurogastroenterol Motil. 2016; 22:272-81. https://doi. org/10.5056/jnm15138.

15. Niesler B, Kapeller J, Hammer C, Rappold G. Serotonin type 3 receptor genes: HTR3A, B, C, D, E. Pharmacogenomics. 2008; 9:501-4. https://doi.org/10.2217/14622416.9.5.501.

16. Miyake A, Mochizuki S, Takemoto Y, Akuzawa S. Molecular cloning of human 5-hydroxytryptamine3 receptor: heterogeneity in distribution and function among species. Mol Pharmacol. 1995; 48:407-16.

17. Davies PA, Pistis M, Hanna MC, Peters JA, Lambert JJ, Hales TG, Kirkness EF. The 5-HT3B subunit is a major determinant of serotonin-receptor function. Nature. 1999; 397:359-63. https://doi.org/10.1038/16941.

18. Niesler B, Frank B, Kapeller J, Rappold GA. Cloning, physical mapping and expression analysis of the human 5-HT3 serotonin receptor-like genes HTR3C, HTR3D and HTR3E. Gene. 2003; 310:101-11.

19. Lennertz L, Wagner M, Frommann I, SchulzeRauschenbach S, Schuhmacher A, Kuhn KU, Pukrop R, Klosterkotter J, Wolwer W, Gaebel W, Rietschel M, Hafner H, Maier W, et al. A coding variant of the novel serotonin receptor subunit 5-HT3E influences sustained attention in 
schizophrenia patients. Eur Neuropsychopharmacol. 2010; 20:414-20. https://doi.org/10.1016/j.euroneuro.2010.02.012.

20. Hammer C, Kapeller J, Endele M, Fischer C, Hebebrand J, Hinney A, Friedel S, Gratacos M, Estivill X, Fichter M, Fernandez-Aranda F, Ehrlich S, Rappold G, et al. Functional variants of the serotonin receptor type $3 \mathrm{~A}$ and $\mathrm{B}$ gene are associated with eating disorders. Pharmacogenet Genomics. 2009; 19:790-9. https://doi.org/10.1097/ FPC.0b013e32833132b3.

21. Hammer C, Cichon S, Muhleisen TW, Haenisch B, Degenhardt F, Mattheisen M, Breuer R, Witt SH, Strohmaier J, Oruc L, Rivas F, Babadjanova G, GrigoroiuSerbanescu M, et al. Replication of functional serotonin receptor type $3 \mathrm{~A}$ and $\mathrm{B}$ variants in bipolar affective disorder: a European multicenter study. Transl Psychiatry. 2012; 2:e103. https://doi.org/10.1038/tp.2012.30.

22. Rehnstrom K, Ylisaukko-oja T, Nummela I, Ellonen P, Kempas E, Vanhala R, von Wendt L, Jarvela I, Peltonen L. Allelic variants in HTR3C show association with autism. Am J Med Genet B Neuropsychiatr Genet. 2009; 150B:741-6. https://doi.org/10.1002/ajmg.b.30882.

23. Lennertz L, Wagner M, Grabe HJ, Franke PE, Guttenthaler V, Rampacher F, Schulze-Rauschenbach S, Vogeley A, Benninghoff J, Ruhrmann S, Pukrop R, Klosterkotter J, Falkai P, et al. 5-HT3 receptor influences the washing phenotype and visual organization in obsessive-compulsive disorder supporting 5-HT3 receptor antagonists as novel treatment option. Eur Neuropsychopharmacol. 2014; 24:86-94. https://doi. org/10.1016/j.euroneuro.2013.07.003.

24. Enoch MA, Gorodetsky E, Hodgkinson C, Roy A, Goldman D. Functional genetic variants that increase synaptic serotonin and 5-HT3 receptor sensitivity predict alcohol and drug dependence. Mol Psychiatry. 2011; 16:1139-46. https://doi.org/10.1038/mp.2010.94.

25. Yang J, Li MD. Association and interaction analyses of 5-HT3 receptor and serotonin transporter genes with alcohol, cocaine, and nicotine dependence using the SAGE data. Hum Genet. 2014; 133:905-18. https://doi. org/10.1007/s00439-014-1431-7.
26. Kilpatrick LA, Labus JS, Coveleskie K, Hammer C, Rappold G, Tillisch K, Bueller JA, Suyenobu B, Jarcho JM, McRoberts JA, Niesler B, Mayer EA. The HTR3A polymorphism c. $-42 \mathrm{C}>\mathrm{T}$ is associated with amygdala responsiveness in patients with irritable bowel syndrome. Gastroenterology. 2011; 140:1943-51. https:// doi.org/10.1053/j.gastro.2011.03.011.

27. Walstab J, Rappold G, Niesler B. 5-HT(3) receptors: role in disease and target of drugs. Pharmacol Ther. 2010; 128:146-69. https://doi.org/10.1016/j.pharmthera.2010.07.001.

28. Mantel N, Haenszel W. Statistical aspects of the analysis of data from retrospective studies of disease. J Natl Cancer Inst. 1959; 22:719-48.

29. Stang A. Critical evaluation of the Newcastle-Ottawa scale for the assessment of the quality of nonrandomized studies in meta-analyses. Eur J Epidemiol. 2010; 25:603-5. https:// doi.org/10.1007/s10654-010-9491-z.

30. Thakkinstian A, McElduff P, D'Este C, Duffy D, Attia J. A method for meta-analysis of molecular association studies. Stat Med. 2005; 24:1291-306. https://doi.org/10.1002/ $\operatorname{sim} .2010$.

31. Dupont WD, Plummer WD Jr. Power and sample size calculations. A review and computer program. Control Clin Trials. 1990; 11:116-28.

32. Colditz GA, Burdick E, Mosteller F. Heterogeneity in metaanalysis of data from epidemiologic studies: a commentary. Am J Epidemiol. 1995; 142:371-82.

33. DerSimonian R. Meta-analysis in the design and monitoring of clinical trials. Stat Med. 1996; 15:1237-48; discussion 49-52. https://doi.org/10.1002/(SICI)10970258(19960630)15:12<1237::AID-SIM301>3.0.CO;2-N.

34. Egger M, Davey Smith G, Schneider M, Minder C. Bias in meta-analysis detected by a simple, graphical test. BMJ. 1997; 315:629-34. 